\title{
Gynecomastia: physiopathology, evaluation and treatment
}

\author{
Ginecomastia: fisiopatologia, avaliação e tratamento
}

\author{
Alfredo Carlos Simões Dornellas de Barros', Marcelo de Castro Moura Sampaio" \\ Mastology Department, Hospital Sírio-Libanês, São Paulo, Brazil
}

\begin{abstract}
'MD, PhD. Coordinator of the Mastology Department, Hospital Sírio-Libanês, and Researcher in the Discipline of Human Structural Topography (LIM 02), Faculdade de Medicina da Universidade de São Paulo (FMUSP), São Paulo, Brasil.

"MD, MSc. Plastic Surgeon in the Mastology Department, Hospital Sírio-Libanês, São Paulo, Brasil.
\end{abstract}

KEY WORDS:

Breast.

Gynecomastia.

Surgery.

Adolescent.

Endocrine system diseases.

\section{PALAVRAS-CHAVE:}

Mama.

Ginecomastia.

Cirurgia.

Adolescente

Doenças do sistema endócrino.

\begin{abstract}
Gynecomastia (GM) is characterized by enlargement of the male breast, caused by glandular proliferation and fat deposition. GM is common and occurs in adolescents, adults and in old age. The aim of this review is to discuss the pathophysiology, etiology, evaluation and therapy of GM. A hormonal imbalance between estrogens and androgens is the key hallmark of GM generation. The etiology of GM is attributable to physiological factors, endocrine tumors or dysfunctions, non-endocrine diseases, drug use or idiopathic causes. Clinical evaluation must address diagnostic confirmation, search for an etiological factor and classify GM into severity grades to guide the treatment. A proposal for tailored therapy is presented. Weight loss, reassurance, pharmacotherapy with tamoxifen and surgical correction are the therapeutic options. For long-standing GM, the best results are generally achieved through surgery, combining liposuction and mammary adenectomy.
\end{abstract}

\section{RESUMO}

A ginecomastia (GM) é caracterizada pelo aumento do volume mamário em homens, provocada por proliferação glandular e depósito de gordura. É comum e pode ocorrer em adolescentes, adultos e idosos. O objetivo desta revisão é discutir a fisiopatologia, etiologia, avaliação clínica e terapia da GM. Um desequilíbrio entre estrogênios e androgênios é reconhecido como a condição fundamental para a determinação do quadro, podendo ser atribuído a fatores fisiológicos, tumores ou distúrbios endócrinos, doenças não-endócrinas, uso de drogas ou ser de causa idiopática. A avaliação clínica deve enfocar a confirmação diagnóstica, a procura de uma causa específica e a classificação em graus de gravidade para orientar o tratamento. Um roteiro de conduta individualizada é apresentado, variando entre perda de peso e explicações verbais, tratamento com tamoxifeno e correção cirúrgica. Para casos de GM persistente, os melhores resultados são obtidos em geral mediante abordagem cirúrgica, combinando lipoaspiração e adenectomia mamária.

\section{INTRODUCTION}

Gynecomastia (GM) is a benign condition characterized by enlargement of the male breast, which is attributable to proliferation of the glandular tissue and local fat deposition. It can be physically uncomfortable, psychologically distressing and may have a negative impact on selfconfidence and body image. Pseudogynecomastia is common in obese men, and consists of lipomastia alone, without glandular proliferation. This condition, together with neonatal transient breast hypertrophy caused by the high estrogenic milieu of pregnancy, should not be considered to be true GM, and these are beyond the scope of this paper.

Male breast tissue proliferation can occur at all ages and may be unilateral or bilateral. It has been estimated that $30 \%$ to $60 \%$ of boys exhibit GM during adolescence and that at least one third of the adult male population may be affected. The differences between samples can be accounted for by the criteria used to define them and the diversity of the samples studied. ${ }^{1-3}$ The highest prevalence of GM is found in old age, when it is detected in up to $65 \%$ of men. ${ }^{4,5}$

GM is common and clinically important. Nevertheless, major gaps in knowledge regarding its modern epidemiology exist, and it has not been proven whether the apparent rise in its incidence is true. Nonetheless, over recent decades, there have been substantial increases in the use of anabolic steroids and in environmental contamination with xenoestrogens or estrogen-like substances that, at least theoretically, can stimulate glandular proliferation of the male breast. ${ }^{6,7}$

This review addresses the pathophysiology, etiology and clinical evaluation of GM and discusses the selection of patients for tailored therapy, which remains a challenge for physicians. We 
performed a search for published scientific papers in PubMed, SciELO and the Cochrane Database of Systematic Reviews (Table 1), covering 2000 to 2011 .

\section{PHYSIOPATHOLOGY}

It is well known that male breast tissue contain protein receptors for estrogens and androgens. ${ }^{6,8,9}$ Whereas estrogens stimulate the proliferation of the mammary ductules, androgens, on the contrary, inhibit the process. ${ }^{10,11} \mathrm{~A}$ hormonal imbalance between these factors is the key hallmark for GM generation. ${ }^{12-14}$ The estrogen/androgen imbalance may be attributable to increased levels of free estrogens secreted by the testes or adrenal glands, extraglandular aromatization of estrogen precursors, decreased estrogen degradation, exposure to estrogen-like chemicals or exogenous estrogens and use of drugs that cause displacement of more estrogen than androgen from sex hormone-binding globulin (SHBG) ${ }^{10,13}$ On the other side, the imbalance may result from decreased androgen production in the testes, increased binding of androgens (relative to estrogens) by SHBG, altered androgen metabolism, drug-induced displacement of androgens from their receptors and androgen receptor defects. ${ }^{15-17}$

In males, the testes secrete about $95 \%$ of the circulating testosterone, $15 \%$ of the estradiol and $5 \%$ of the estrone that are produced daily. In normal men, the serum concentration of estrogens is very low. Most of the estrogens (80\%) are produced by peripheral conversion of two precursors, androstenedione and testosterone, respectively in estrone and estradiol, under the influence of the enzyme aromatase, which plays a pivotal role in male secretion of estrogens. Peripheral conversion occurs mainly in the intramammary and subcutaneous fat, but is also seen in the liver, skin, muscles and kidneys. Aromatase activity increases both with age and with elevation of the body mass index. ${ }^{13-16}$

Continuous environmental exposure to substances with weak estrogen-agonist action, probably due to epigenetic mechanisms, theoretically can induce the development of GM. Endocrine-disrupting chemicals in consumer products, air pollutants, radiation, organochlorine pesticides, plastics, plasticizers, fuels and polycyclic aromatic hydrocarbons are listed among these substances. Improved exposure assessment methods will help advance future epidemiological and related interdisciplinary research on the relationship between the environment and GM. ${ }^{18}$

Table 1. Database search results

\begin{tabular}{lcc} 
Database & Search & Results \\
PubMed & gynecomastia & 13 reviews \\
\cline { 2 - 3 } & gynaecomastia & 3 clinical trials \\
\cline { 2 - 3 } SciELO & ginecomastia & 1 case-control study \\
& gynecomastia & 5 case series \\
Cochrane Library & gynecomastia & 2 reviews \\
& gynaecomastia & none \\
\hline
\end{tabular}

The first study showing the link between GM and environmental chemicals was published by Durmaz et al. ${ }^{19}$ These authors compared the plasma phthalate levels in 40 diagnosed pubertal GM cases with the levels in 21 age-matched boys without GM. They observed that phthalate metabolite concentrations in the plasma were significantly higher in the adolescents with GM than in the control group $(\mathrm{P}<0.01)$. Phthalates are esters of alphaphthalic acid with antiandrogenic and estrogenic effects that are found in personal care products (cosmetics, perfumes and clothing), paints, solvents, insecticides, plasticizers, food, water and pharmaceuticals. ${ }^{6,20,21}$

Reinforcing the evidence suggesting that there is a relationship between chemicals and GM, it is worthwhile mentioning the epidemic onset observed among Haitian refugees in 1981 about four months after arrival in United States detention centers. ${ }^{22}$ After analyzing all identifiable environmental exposures, it was then found that phenothrin, a multi-insecticide contained in sprays that they had used was the causative agent. ${ }^{23}$ It is now widely known that phenothrin has antiandrogenic activity.

There is evidence that enlarged male breast glands contain luteinizing hormone ( $\mathrm{LH}$ ) and human chorionic gonadotropin (hCG) receptors. ${ }^{24}$ The role of these receptors has yet to be elucidated, but it is reasonable to suppose that their activation could decrease the androgenic effects by altering the local metabolism. It has also been reported that LH and hCG reduce the concentration of androgen receptors in the skin. ${ }^{25}$

Findings of lobular structures in microscopic analysis on GM tissue are very rare. Progesterone appears to be required to form true glandular acini acting in synergy with insulin growth factor-1 (IGF-1). ${ }^{26}$ Under some clinical conditions, such as hyperthyroidism and hepatic cirrhosis associated with GM, it is possible to detect elevated serum progesterone concentrations. ${ }^{27,28}$

Another hormonal action that stimulates breast tissue in men is observed secondary to hyperprolactinemia. Prolactin receptors have been demonstrated in GM, and hyperprolactinemia probably plays an indirect role in GM, since it causes central hypogonadism and alters the androgen/estrogen ratio..$^{14,29,30}$ However, it is clear that most men with GM do not have elevated serum prolactin levels and not all men with hyperprolactinemia develop GM. ${ }^{14}$ Nonetheless, it has been shown in cultured breast cancer cells that prolactin and progesterone receptors may be coexpressed and may cross-regulate each expression. ${ }^{31}$ Similar crosstalk may exist in relation to growth hormones, thus giving rise to a permissive role for estrogen activity, probably via the IGF-1 receptor. ${ }^{32}$

GM is a multifactorial disease and many conditions may be associated with it. Table 2 outlines the various specific causes of GM. According to Braunstein, ${ }^{33}$ almost two-thirds of the patients have physiological GM (approximately 25\%), no underlying detected abnormality (idiopathic, approximately 25\%) or drug- 
induced breast development (up to 20\%). The frequencies of some of the remaining causes have been estimated as follows: cirrhosis, $8 \%$; primary hypogonadism, $8 \%$; testicular tumors, $3 \%$; secondary hypogonadism, $2 \%$; hyperthyroidism, $1.5 \%$; and renal disease, $1 \%$

\section{Pubertal GM}

Mild degrees of pubertal GM generally appear at 13 or 14 years of age, last for 6-12 months and then spontaneously regress in 95\% of the cases. ${ }^{13}$ The glandular enlargement may be asymmetric and tender. The hypertrophy may reach severe proportions, leading to an effeminate appearance in boys. Such occurrences may alter self-perceptions, especially in the sexual sphere. ${ }^{34}$

Relative excess of serum levels of estrogens compared with androgens is implicated in the pathogenesis, due to estradiol production rising sooner than testosterone production. Some other factors may also interact, and usually there is concomitant elevation in serum IGF-1 concentrations. Interestingly, a family history has been elicited in more than half of the patients with persistent pubertal GM. ${ }^{17,34}$

\section{Aging GM}

Older men over the age of 65 years often present relative hypogonadism with a decline in plasma testosterone levels, elevation of SHBG and decrease in free testosterone. Furthermore, there is progressive adiposity favoring peripheral aromatase activity. ${ }^{35,36}$ Several comorbidities may be common at this age, and any medication used may contribute towards provoking or aggravating GM. ${ }^{14}$

\section{Endocrine tumors}

Benign testicular tumors (Sertoli or Leydig cell tumors) may secrete estradiol. Secondary suppression of LH levels interferes negatively with testosterone synthesis. The elevated estrogen levels raise the serum concentration of SHBG, which preferentially binds testosterone, thereby lowering the free testosterone levels. ${ }^{12}$

Choriocarcinoma and other germ cell tumors produce hCG and stimulate testicular cells (Leydig) to secrete estradiol, and furthermore, often cause GM. These tumors may be palpable or be detected only by means of ultrasound. Other hCG secreting tumors of ectopic origin may lead to GM (e.g. carcinomas of the lungs, liver, stomach and kidneys). ${ }^{13-17}$

Pituitary adenomas producing prolactin (prolactinomas) may also induce GM. ${ }^{17}$

Adrenocortical tumors are generally large malignant types of neoplasia, with predominant incidence in young and middle-aged men. They are feminizing tumors with direct secretion of estrogens and steroid precursors, like androstenedione. The serum estrogen elevation also suppresses LH-mediated testosterone production. ${ }^{14}$
Table 2. Etiology of gynecomastia

\begin{tabular}{ll}
$\begin{array}{l}\text { Causes } \\
\text { Physiological factors }\end{array}$ & $\begin{array}{l}\text { Puberty or aging } \\
\text { Endocrine tumors }\end{array}$ \\
$\begin{array}{l}\text { or ectopic hCG-secretion } \\
\text { Hypogonadism, hyperthyroidism, obesity or } \\
\text { Endocrine dysfunctions }\end{array}$ & $\begin{array}{l}\text { Cirrhosis, renal failure or HIV } \\
\text { Medications, anabolic steroids or illicit } \\
\text { Non-endocrine diseases }\end{array}$ \\
\hline Drug-induced factors & \\
\hline Idiopathic factors &
\end{tabular}

\section{Endocrine dysfunctions}

Severe hyperthyroidism increases serum SHBG. Since estradiol binds less avidly to SHBG than does testosterone, there appears to be an increase in the ratio of free estradiol to free testosterone, thus resulting in clinically evident GM in 10 to $40 \%$ of the patients. ${ }^{37}$

Primary gonadal failure as a result of testicular trauma, chemotherapy, mumps, orchitis and leprosy can cause GM by lowering the serum testosterone levels, inducing elevation of $\mathrm{LH}$ and stimulating the remaining Leydig cells to secrete estrogens. ${ }^{12}$ Klinefelter syndrome is a chromosomal disorder (47 XXY karyotype) associated with hypogonadism and infertility; in these men, GM is seen in almost $70 \%$. The reason why the presence of an extra $\mathrm{X}$ chromosome is linked to GM is unclear. ${ }^{14,38}$ Male pseudohermaphroditism with Morris syndrome (testicular feminization) is often associated with normal female breast appearance due to gonadal estrogen production. ${ }^{33}$ Low testosterone and elevated LH levels indicate primary hypogonadism. Findings of low testosterone levels with normal $\mathrm{LH}$ assays denote secondary testicular failure. ${ }^{33}$

It is noteworthy that men with long-standing type 1 diabetes may develop diabetic mastopathy, presenting hard diffuse enlargements of one or both breasts. ${ }^{39}$ An inflammatory lesion characterized by lymphocytic infiltration of the mammary ducts and lobules is found microscopically. ${ }^{39}$

Other endocrine-metabolic conditions related to the development of GM include metabolic syndrome, refeeding after severe starvation and substantial weight loss and functional hyperprolactinemia. ${ }^{12,14}$

\section{Non-endocrine diseases}

The chief sex hormone abnormalities in cases of liver cirrhosis are decreased serum testosterone levels and increased estradiol levels. ${ }^{39}$ The mechanisms that cause liver cirrhosis to lead to GM in a small percentage of cases have yet to be elucidated. The causes are probably multifactorial. Men with chronic renal failure are often hypogonadal, with defects in testicular steroidogenesis. ${ }^{12}$ Many of these men develop GM.

In men with HIV, GM occurs in $2-3 \%{ }^{40} \mathrm{GM}$ can be triggered either by lipodystrophy or by highly active antiretroviral therapy. 


\section{Drug induction}

Drug-induced GM merits deep consideration as it may account for as many as $25 \%$ of all cases of new-onset GM in adults. Even though the mechanisms through which a long list of drugs can cause GM are not fully clear, they are derived from estrogen-like activities, stimulation of testicular production of estrogens, inhibition of testosterone synthesis or blockade of androgen action. ${ }^{12,41}$

One of the medications most frequently associated with GM is the diuretic spironolactone, which is a competitive antagonist of aldosterone. Spironolactone also inhibits testosterone production in the testes, enhances the aromatization of testosterone to estradiol and binds to androgen receptors in some tissues, thereby acting as an antiandrogenic substance. ${ }^{41,42}$

Androgen deprivation therapy for prostate cancer frequently presents GM as a side effect. The incidence of GM depends on the type and duration of the hormone therapy, but it can be as high as $40-70 \%{ }^{43}$

Some illicit drugs, such as cocaine, heroin and amphetamines, and other abused drugs, are commonly associated with GM. Marijuana is believed to interfere with estrogen receptors and acts as a phytoestrogen. ${ }^{44}$

Doping with anabolic androgenic steroids, gonadotropins and growth hormones for power sports and weight training is rampant. In male athletes, these iatrogenic drugs may suppress spermatogenesis and/or induce GM. ${ }^{45}$

Table 3 outlines the common pharmaceutical products that may cause GM with prolonged use.

\section{Idiopathic GM}

So far, at least 20 clinical conditions and 30 medications have been implicated in relation to causing GM. However, the etiology of GM is still only understood to a limited extent, and up to $50 \%$ of the cases may have no obvious cause..$^{33}$ Given the high frequency of idiopathic GM, we hypothesize that multiple environmental endocrine disruptors are likely to be involved in excessive breast development in men.

Table 3. Common medications causing gynecomastia ${ }^{41}$

\begin{tabular}{|c|c|}
\hline Type of agent & Medications \\
\hline Antiandrogens & $\begin{array}{l}\text { Bicalutamide, cyproterone, flutamide, finasteride, } \\
\text { spironolactone }\end{array}$ \\
\hline Antibiotics & Isoniazid, ketoconazole, metronidazole \\
\hline Antihypertensives & $\begin{array}{l}\text { Amlodipine, captopril, enalapril, nifedipine, reserpine, } \\
\text { verapamil }\end{array}$ \\
\hline Chemotherapeutic agents & Cyclophosphamide, methotrexate \\
\hline Diuretic & Spironolactone \\
\hline Gastrointestinal agents & Cimetidine, omeprazole, metoclopramide, ranitidine \\
\hline Hormones & Androgens, anabolic steroids, estrogens, growth hormone \\
\hline Psychiatric agents & $\begin{array}{l}\text { Diazepam, haloperidol, phenothiazine, tricyclic } \\
\text { antidepressants }\end{array}$ \\
\hline Others & $\begin{array}{l}\text { Amiodarone, antiretrovirals, digitalis, domperidone, statins, } \\
\text { theophylline }\end{array}$ \\
\hline
\end{tabular}

\section{EVALUATION}

Clinical evaluations on men with enlarged breast tissue have three phases: 1) making the diagnosis of true GM; 2) trying to find an etiological factor to further guide case management; and 3) classifying into severity grades.

\section{Making the diagnosis}

Differentiation of true GM from pseudogynecomastia (local fat deposition alone) and tumors is based on physical examination by means of inspection and palpation. Initially, the patient must disrobe from the waist upwards, for inspection in a seated position: with the arms relaxed, with the arms raised, and with the hands pressed against the hips to contract the pectoral muscles. After palpation of the axillary nodes, the patient is asked to lie down in a supine position with his hands clasped beneath his head. First, the examiner carefully flat-palpates with his fingers to detect glandular tissue, and then, with his thumb and forefinger separated, slowly brings the fingers together from either side of the breast. ${ }^{13}$ In true GM cases, a disc of firm tissue, concentric with the nipple-areolar complex, is felt. Patients with pseudogynecomastia do not show mound resistance of this nature, and no firm tissue is found. ${ }^{13}$

Breast carcinoma usually consists of a unilateral hard irregular mass, located outside the areola and may be accompanied by skin dimpling, nipple retraction and axillary lymphadenopathy. Other local problems, such as dermoid cysts, lymphangiomas, lipomas, post-trauma hematomas, neurofibromas and several benign tumors are usually easily distinguished. Any lesion that is suspected to be malignant should be evaluated by means of coreneedle or excisional biopsies.

GM is clinically bilateral in approximately half of the patients. ${ }^{13}$ Nipple discharge is very uncommon. ${ }^{13-17}$

Ruling out the possible presence of breast carcinoma is paramount, particularly in adults with unilateral enlargements, family histories of breast cancer or Klinefelter syndrome. Mammography is the primary imaging method when there is any suspicion of cancer. As a predictor of malignancy, mammography has sensitivity of $90 \%$ and specificity of $92 \%{ }^{46}$

Sonography has been widely used in GM cases. It is important to recognize the various patterns of GM in order to avoid unnecessary worries. The typical findings include hypoechoic retroareolar masses (nodular, poorly defined or flame-shaped), with increased anteroposterior depth at the nipple. ${ }^{47}$

If differentiation between GM and breast carcinoma cannot be made on the basis of clinical and imaging findings, the patient should undergo percutaneous biopsy. Microscopically, GM is characterized by proliferation of the ductules, without terminal acini, in fibroconnective stroma (Figure 1). In the early onset stage (florid phase), there is extensive ductal hyperplasia; over time, the glandular elements become less prominent and fibrosis becomes the main finding (fibrous phase). Although it might be tempting to try to 
establish a correlation between etiological factors and histological appearance, no such correlation has ever been identified.

The current wisdom is to endorse the concept that men with GM are not at high risk of breast cancer. ${ }^{48}$ However, certain factors linked with increased incidence of GM also are related to cancer, such as estrogen use and androgen deficiency. ${ }^{49,50}$ A metaanalysis on seven case-control studies revealed that the breast cancer risk is slightly higher in males with GM. ${ }^{51}$ Klinefelter syndrome is the only condition in which the risk of cancer is worrisome, with a 50 -fold higher risk of developing breast cancer than among men in the general population. ${ }^{52}$

\section{Trying to find an etiological factor}

A detailed history, with attention given to age, medications, duration and onset of breast enlargement, symptoms of tenderness or pain, recreational drug use and anabolic steroid use, is crucial. The general physical examination may reveal signs of thyroid disease, hypogonadism or other conditions. Abdominal masses may be found in patients with adrenocortical carcinomas. The investigation should specifically pay attention both to the breasts and to the genitals.

Further work-up includes screening laboratory tests and ultrasonography on the adrenal glands and testes. However, in practical terms, even extensive testing is unlikely to reveal anything when there is no history or physical examination suggestive of an underlying pathological cause..$^{12,13,53-55}$

As a routine, we recommend serum assaying of the following hormones: testosterone, free (bioavailable) testosterone, estradiol, hCG, LH, FSH, prolactin, T3, T4 and TSH. Testosterone, free (bioavailable) testosterone and LH should be measured in the morning, since they have a circadian rhythm with the highest values in the early hours.

\section{Classifying into severity grades}

GM shows a gradation of clinical types that range from simple areolar protrusion to breasts with a female appearance. The main clinical features characterizing GM are breast swelling, increased areolar diameter, presence of an anomalous inframammary fold, glandular ptosis and skin redundancy.

There are several morphological classifications for GM..$^{53-57}$ For practical purposes, we have adopted the clinical classification of Cordova and Moschella, ${ }^{56}$ with some modifications, since this is simple and stringent. This classification takes into account the different relationships between the structural components of the breast, in particular the inframammary fold and nipple-areola complex (NAC), which is the watershed between mild forms and serious forms.

Based upon this classification, in a standing position we classify all types of GM into four grades of increasing severity from I to IV, as follows (Figures 2, 3, 4 and 5):

- Grade I: Increased diameter and slight protrusion limited to the areolar region;
- Grade II: Moderate hypertrophy of all the structural components of the breast, with the NAC above the inframammary fold;

- Grade III: Major breast hypertrophy, glandular ptosis and the NAC at the same height as or as much as $1 \mathrm{~cm}$ below the inframammary fold;

- Grade IV: Major breast hypertrophy, with skin redundancy, severe ptosis and the NAC positioned more than $1 \mathrm{~cm}$ below the inframammary fold.

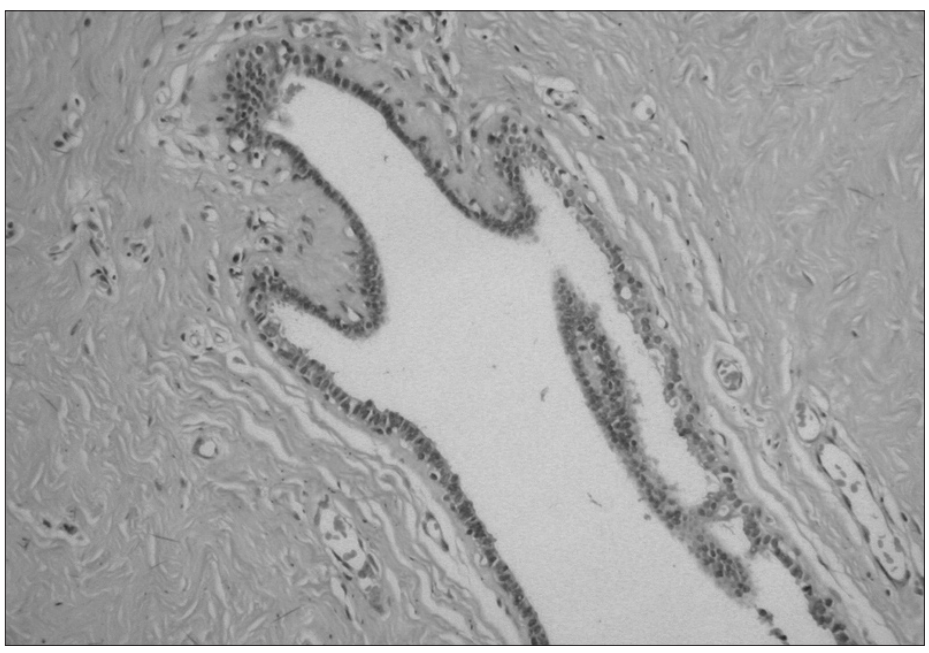

Figure 1. Microscopic findings of gynecomastia characterized by dense fibrous stroma and dilated ductules without lobules (hematoxylin and eosin, $200 \mathrm{x}$ ).

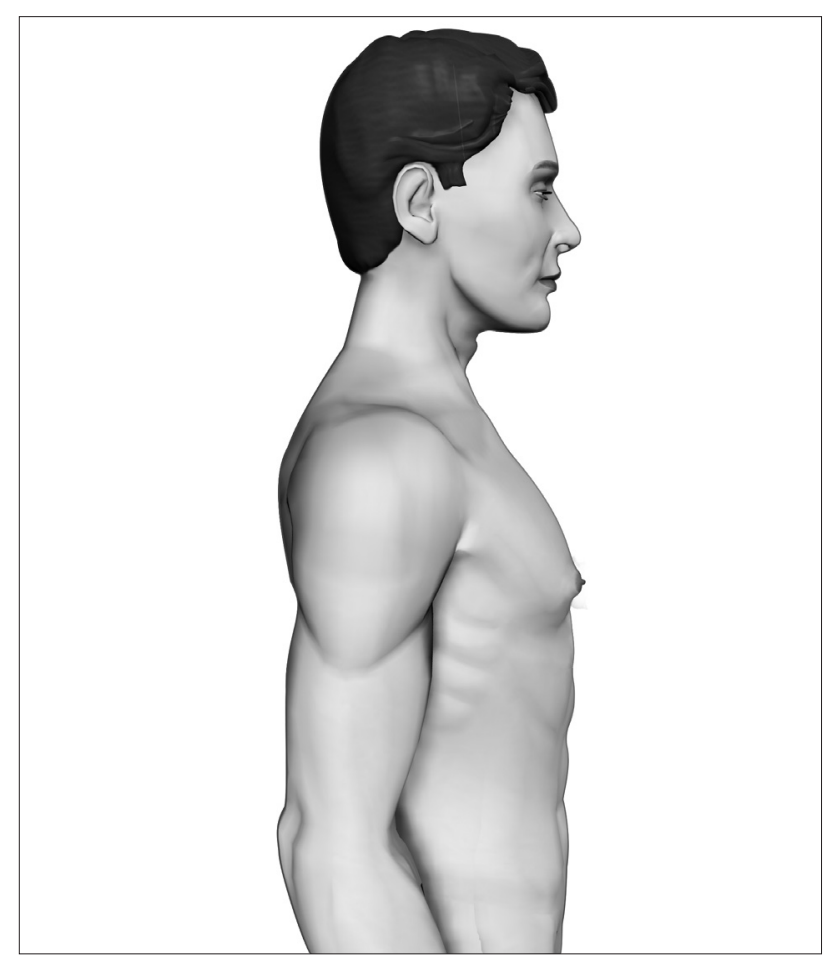

Figure 2. Grade I - Increased diameter and slight protrusion limited to the areolar region. 


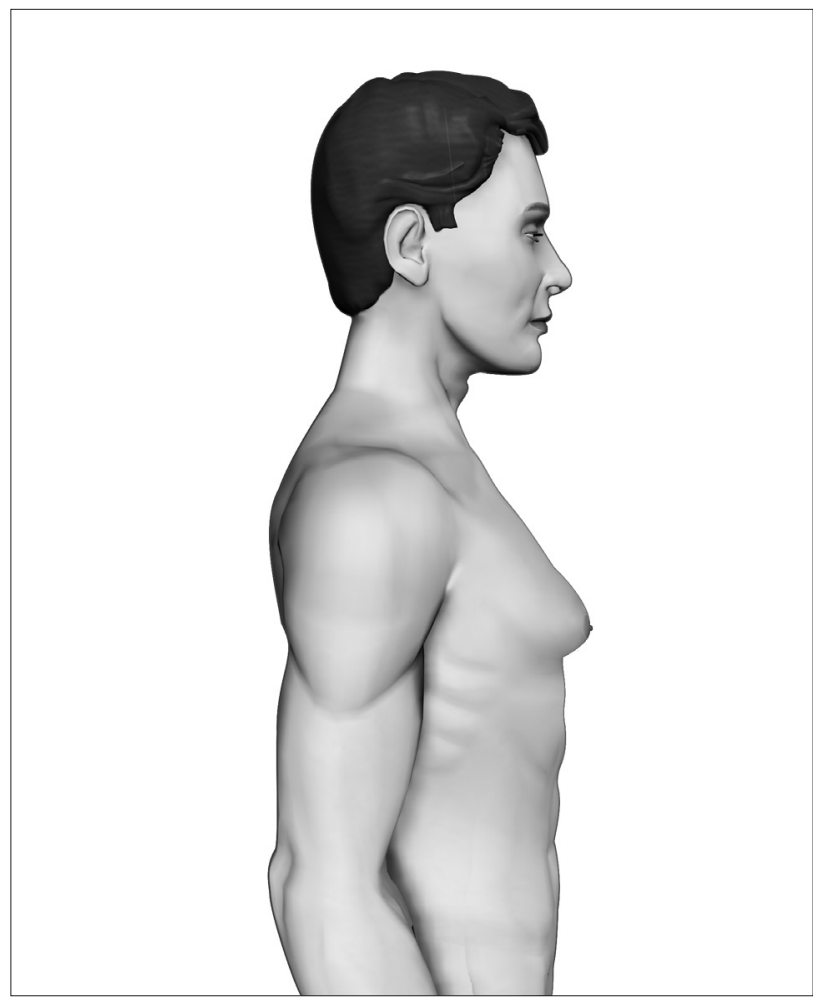

Figure 3. Grade II - Moderate hypertrophy of the breast with the nipple-areolar complex above the inframammary fold.

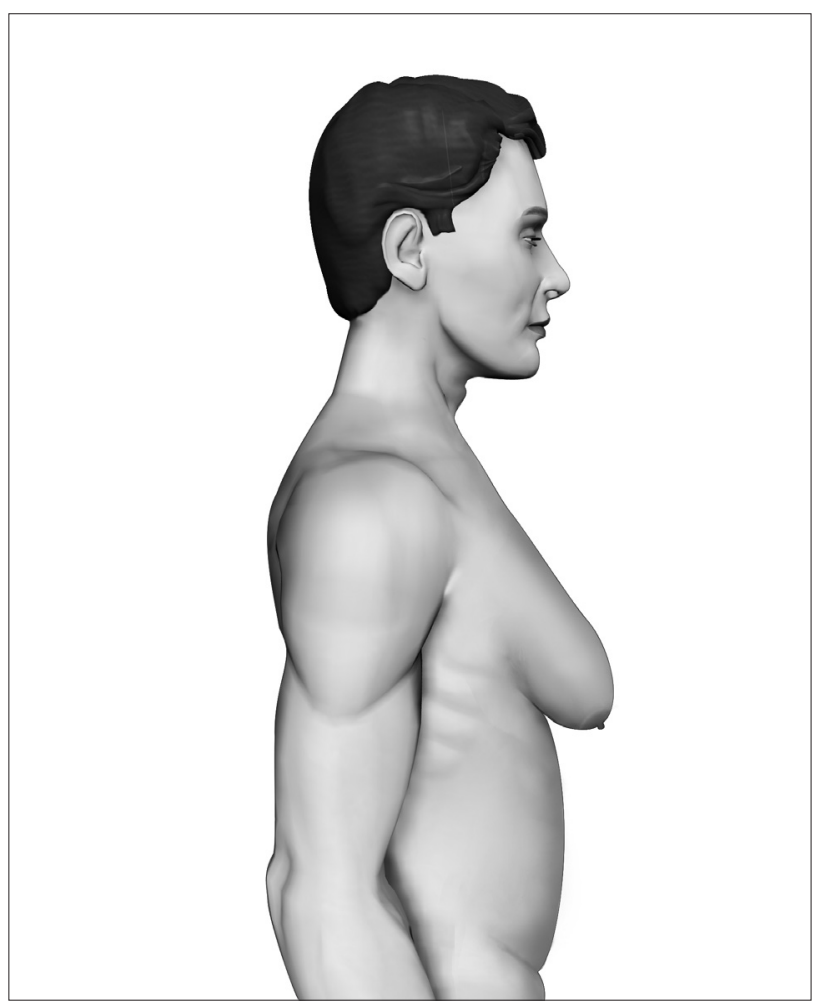

Figure 5. Grade IV - Major breast hypertrophy with skin redundancy, severe ptosis and the nipple-areolar complex positioned more than $1 \mathrm{~cm}$ below the inframammary fold.

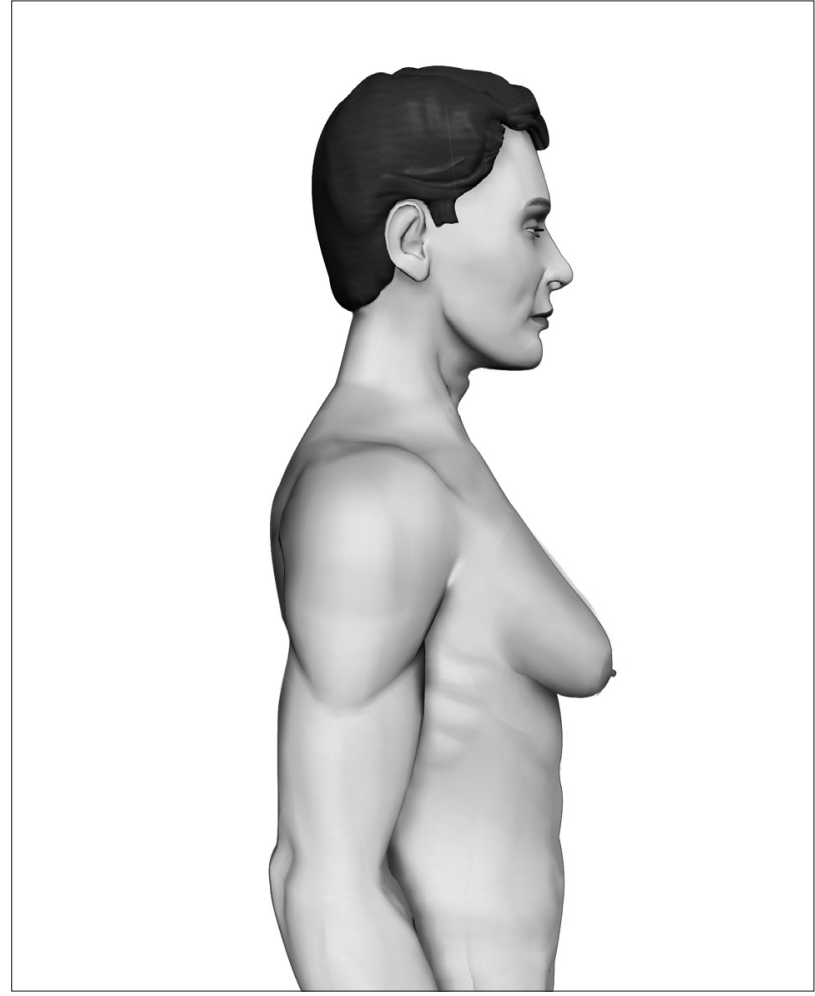

Figure 4. Grade III - Major hypertrophy of the breast with glandular ptosis and the nipple-areolar complex situated at the same height as or as much as $1 \mathrm{~cm}$ below the inframammary fold.

\section{TREATMENT}

\section{General measures}

If the GM is slight, without noteworthy psychological repercussion and the appropriate work-up does not reveal any underlying disease and only shows weight loss, reassurance and periodic follow-up visits (every 3-6 months) are recommended. Reassurance is widely regarded as the safest and most reasonable form of treatment, given that the condition is usually self-limiting and asymptomatic. ${ }^{58}$

For mild enlargements in pubertal boys, the simplest therapeutic approach is verbal explanation and reassurance regarding the signs and symptoms. Reassurance should be based on full and authoritative explanations about the common transient hormonal imbalance at this age, the natural involution of the condition and the absence of later sexual and fertility effects. ${ }^{3-13}$

Although fibroglandular overgrowth may also be present, this is typically overwhelmed in obese boys by the surrounding fat accumulation. For this reason and, equally as important, for other developmental and psychological reasons, a weight loss program (diet and physical exercises) should be the first-line treatment.

If possible, any causative medications or anabolic agents should be immediately withdrawn. Ceasing to use the offending agent may result in regression of GM.

If GM either persists or becomes more severe and is associated with pain, psychological distress or embarrassment caused 
by avoidance of activities in which the chest is exposed, pharmacological and surgical therapeutic options should be considered, especially when the patient wishes to pursue treatment. ${ }^{17}$

\section{Pharmacotherapy}

With the assumption that there is a high possibility that the GM may spontaneously regress, the decision on when to treat is often difficult. ${ }^{33-53}$ However, medical treatment is likely to be beneficial if implemented during the early proliferative phase, before the glandular structure has been replaced by stromal hyalinization and fibrosis. Androgens, antiestrogens and aromatase inhibitors have been tested for GM treatment with some success.

Danazol is an antigonadotropic drug with a weak androgen effect that acts to counterbalance the stimulatory effects of estrogens. A daily dose of 200-600 mg may provide effective control over the symptoms. ${ }^{58,59}$ The side effects are acceptable. Dihydrotestosterone heptanoate, which does not undergo peripheral aromatization, was used in one study for a small number of pubertal cases with excellent results. ${ }^{60}$

Selective estrogen receptor modulators, such as tamoxifen and raloxifene are fairly safe and should be beneficial. The largest series reported is that of Alagaratnam, ${ }^{61}$ who treated 61 cases of idiopathic GM with tamoxifen (40 mg daily for 2-4 months) and achieved complete regression in $80 \%$ of the cases. ${ }^{62-65}$ Other prospective case series have reported success with tamoxifen at a dosage of $20 \mathrm{mg}$ daily.

Two studies have compared tamoxifen with other substances. Ting et al. ${ }^{64}$ reported complete resolution of GM in 18 patients out of 23 treated with tamoxifen (78.2\%), whereas the same regression was found in only eight out of 20 (40\%) with danazol. ${ }^{64}$ Lawrence et al. ${ }^{65}$ retrospectively analyzed 38 adolescents with GM and found that some improvement was seen in $86 \%$ of the patients receiving tamoxifen and in $91 \%$ receiving raloxifene. Nevertheless, a greater proportion showed a significant decrease (> 50\%) with raloxifene $(86 \%)$ rather than with tamoxifen $(41 \%)$.

Three studies have investigated the effectiveness of anastrozole, which is a potent aromatase inhibitor used for treating pubertal GM. While two observational studies with small samples have provided encouragement for the use of anastrozole, ${ }^{66,67}$ a well-designed randomized controlled trial on 80 pubertal boys found that anastrozole was not significantly more effective than placebo for reducing the breast volume calculated from ultrasonography measurements ( $38.5 \%$ versus $31.4 \% ; \mathrm{P}=0.47){ }^{68}$

Tamoxifen was considered superior to anastrozole for prevention of bicalutamide-induced GM in men with prostate cancer. ${ }^{69}$ In a randomized placebo-controlled study, patients receiving tamoxifen presented a significantly reduced risk of GM after three months of treatment ( $20 \mathrm{mg}$ daily), compared with those receiving placebo (risk relative 0.35 ; $95 \%$ confidence interval: 0.13-0.83), whereas the risk for patients treated with anastrozole was not significantly different from the placebo group. ${ }^{70}$
So far, no pharmacological agents for treating GM have been approved in the United States by the Food and Drug Administration. Given the small sample sizes and/or inadequacy of the methodology of published papers, there is no consensus regarding the drug of choice or the optimal duration of treatment. Overall, the use of drugs for GM treatment is only supported by very low quality of evidence, and the uncertainty about the balance between their benefits and potential harm should be highlighted to candidate patients. ${ }^{17}$ Nonetheless, in situations in which after discussing treatment options, scientific evidence, resources and the patient's preference a medication is to be prescribed, we prefer tamoxifen.

\section{Surgical correction}

GM of long duration is unlikely to regress spontaneously and may often progress to dense fibrosis and hyalinization. So far, for long-standing symptomatic GM, medical therapy is less likely to be effective because the stroma is mostly fibrotic. Traditionally, surgery has been the mainstay of therapy in such cases, as well as for men for whom medical therapy fails, is not tolerated or is declined, or for whom tissue removal is preferable for cosmetic reasons. ${ }^{14}$ Even during adolescence, surgery may be the preferred option. In some cases, denial of cosmetic correction or procrastination in providing this may create an additional unnecessary burden on an already overloaded psyche. ${ }^{71}$

The aims of surgical treatment of GM are to restore normal chest contours, eliminate the inframammary fold, correct the NAC position, remove redundant skin, create symmetry between the two halves of the chest and minimize scarring. ${ }^{53}$

There are many surgical techniques and treatment protocols for correcting GM in the literature..$^{54-57,69,73-78}$ In most cases, considering that fibrous and fatty tissues need to be removed, the best results are achieved by combining liposuction and mammary adenectomy. ${ }^{56-71,79}$

The presence of cutaneous ptosis and the amount of excessive skin are decisive in guiding the choice between surgical treatment methods. In our opinion liposuction alone should not be used and is limited only to cases of pure pseudogynecomastia. Surgical treatment of gynecomastia requires an individualized approach. ${ }^{80}$

\section{Grade I}

In grade I, the enlargement is caused solely by glandular proliferation without adipose accumulation. Surgical correction involves mammary adenectomy performed by a semicircular inferior periareolar incision. Liposuction is not required (Figure 6).

\section{Grade II}

Grade II GM is characterized by excessive glandular tissue and local adiposity, with the NAC above the inframammary fold. In these cases, liposuction and surgical excision must be combined in the same operation (Figure 7). We recommend that the procedure 
should begin with vacuum lipoplasty and should be followed by mammary adenectomy by means of a classical periareolar incision. It is worth noting that other incisions may also allow good results, such as intra-areolar, pull-through or endoscopic procedures. ${ }^{56,81-85}$ The dissection flaps must be thin $(0.5 \mathrm{~cm})$, in order to avoid recurrences. Mammary adenectomy without liposuction leads to unsatisfactory outcomes, with an uneven surface or asymmetry.

\section{Grade III}

In grade III, the operation begins with liposuction and is followed by glandular excision with periareolar removal of the tissue. It is necessary to detach the excess skin to obtain a good chest silhouette.

The surgical planning is undertaken bearing in mind the necessity to preclude the stigma of big scars. For the final appearance, it is always preferable for the scars to be restricted to the periareolar area.

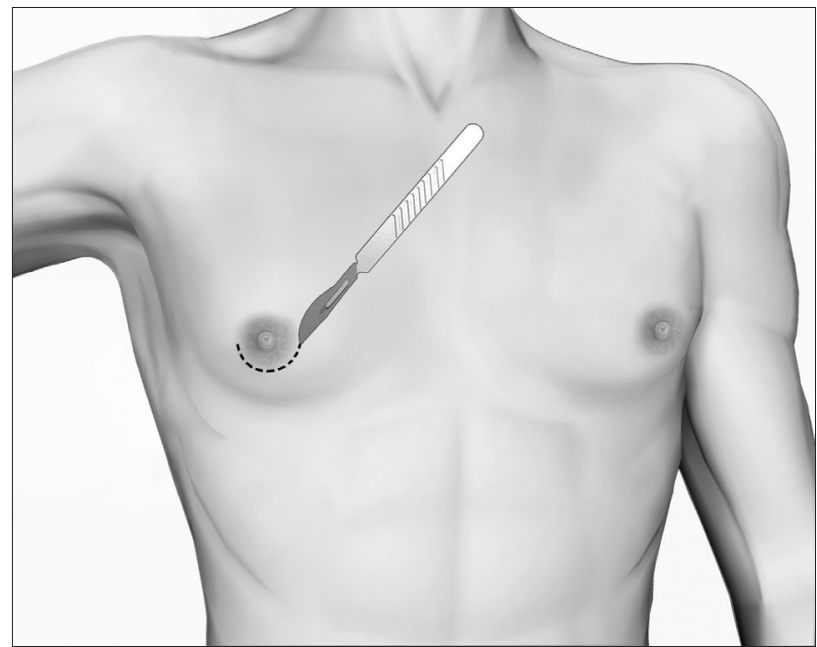

Figure 6. Mammary adenectomy by means of periareolar incision for gynecomastia grade I.

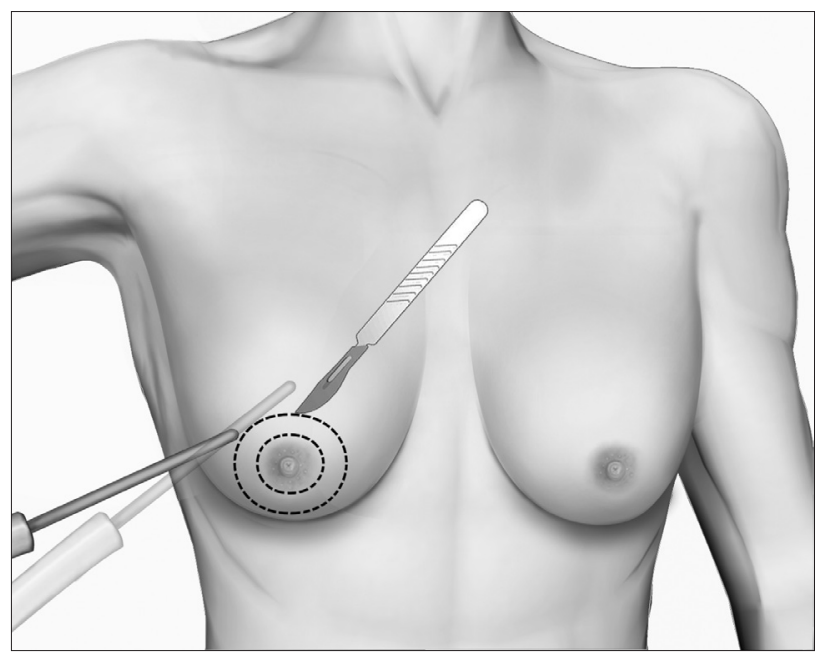

Figure 8. Liposuction followed by double-circle incision mammary adenectomy for gynecomastia grade III.
As a routine, a double-circle incision is performed over the skin, thereby making it possible to remove the epithelial tissue from an annular portion of skin that is as large as needed for each case (Figure 8). Because the epidermis has been removed, round-black suturing is done, which gives rise to a circumferential periareolar scar. ${ }^{56,86}$

\section{Grade IV}

The hallmarks of grade IV GM are severe ptosis and a large amount of redundant skin. One of the techniques for reduction mastoplasty is used to remove gland and skin and flatten the chest outline. ${ }^{56,57,85}$

Inverted T-shaped resection, with NAC migration using superior or superior-medial dermic pedicles, similarly to the procedure for mammoplasty in women, may be used. Other techniques such as those with horizontal or oblique incisions can also be used (Figure 9).

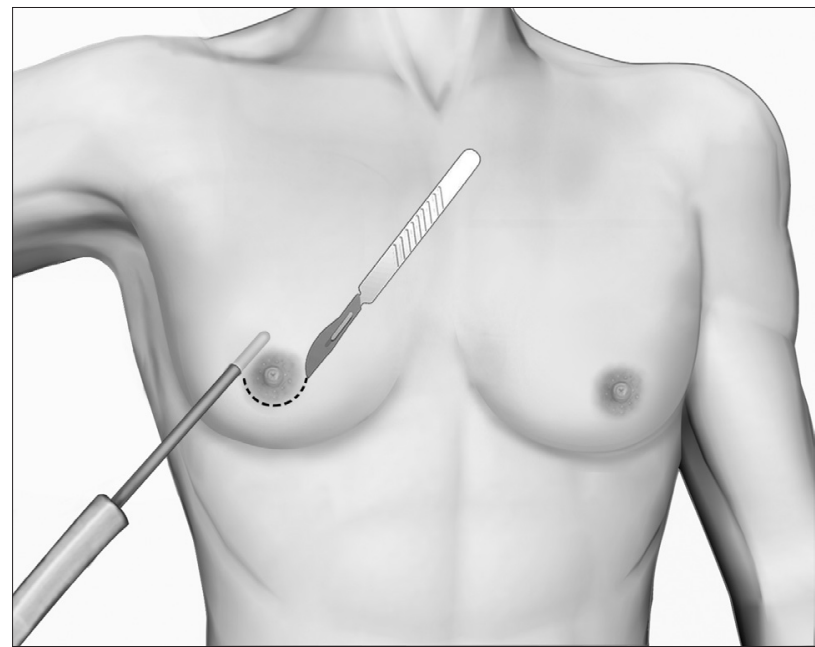

Figure 7. Liposuction followed by mammary adenectomy for gynecomastia grade II.

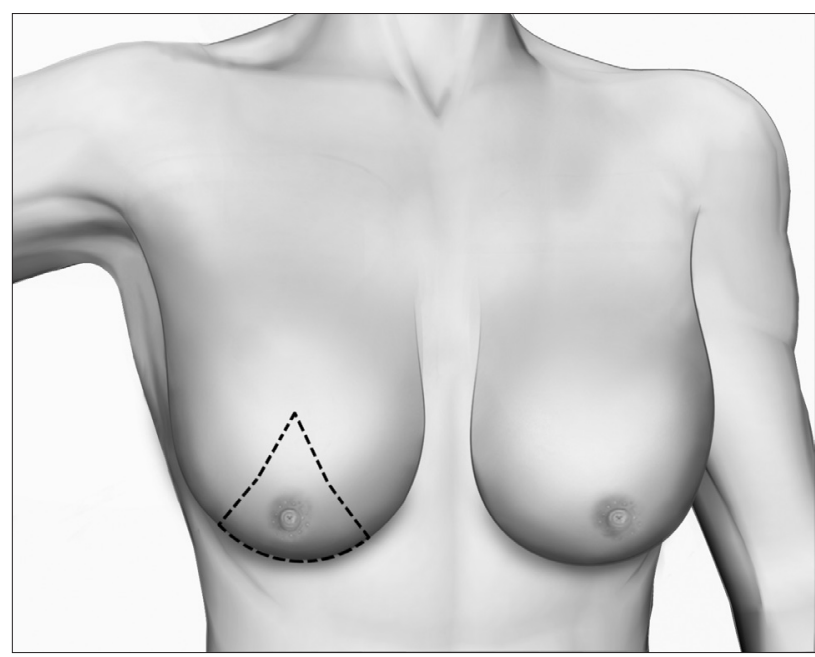

Figure 9. Inverted T-shaped mammary resection with nippleareolar complex migration for gynecomastia grade IV. 
When patients strongly desire to have inconspicuous scars confined to the periareolar region, sequential double-circle skin incisions in a multi-step procedure are a valid option.

Since GM may be harboring neoplasia, histopathological analysis of the resected tissue is mandatory.

Closed suction drains are placed after the excisions and removed when the output over 24 hours has decreased to less than $30 \mathrm{ml}$. Up to $30 \%$ of the patients present postoperative complications, such as bleeding, hematoma and seroma formation. ${ }^{87}$ Large wound areas predispose towards these complications, especially in obese patients.

To facilitate tissue accommodation and achieve an even chest surface, we advise patients to wear elastic compressive garments for a period of 1-2 months. Hypoesthesia of the nipple is very common and is transient. The cosmetic results and patient satisfaction after surgery are high.

\section{CONCLUSIONS}

GM is a common condition that may be attributable to an estrogen/androgen imbalance caused by several etiological factors. After confirming the diagnosis, searching for a specific cause and classifying the case according to severity grade, the therapy for GM should be personalized. Lifestyle guidance, reassurance, medical treatment and surgical correction are valid tailored therapeutic options.

\section{REFERENCES}

1. Georgiadis E, Papandreou L, Evangelopoulou C, et al. Incidence of gynaecomastia in 954 young males and its relationship to somatometric parameters. Ann Hum Biol. 1994;21 (6):579-87.

2. Nuttall FQ. Gynecomastia as a physical finding in normal men. J Clin Endocrinol Metab. 1979;48(2):338-40.

3. Nydick M, Bustos J, Dale JH Jr, Rawson RW. Gynecomastia in adolescent boys. JAMA. 1961;178:449-54.

4. Niewoehner CB, Nuttall FQ. Gynecomastia in a hospitalized male population. Am J Med. 1984;77(4):633-8.

5. Bannayan GA, Hajdu SI. Gynecomastia: clinicopathologic study of 351 cases. Am J Clin Pathol. 1972:57(4):431-7.

6. Moore NP. The oestrogenic potential of the phthalate esters. Reprod Toxicol. 2000;14(3):183-92.

7. Diamanti-Kandarakis E, Bourguignon JP, Giudice LC, et al. Endocrinedisrupting chemicals: an Endocrine Society scientific statement. Endocr Rev. 2009;30(4):293-342.

8. Sasano H, Kimura M, Shizawa S, Kimura N, Nagura H. Aromatase and steroid receptors in gynecomastia and male breast carcinoma: an immunohistochemical study. J Clin Endocrinol Metabol. 1996;81(8):3063-7.

9. Calzada L, Torrs-Calleja J, Martinez JM, Pedrón N. Measurement of androgen and estrogen receptors in breast tissue from subjects with anabolic steroid-dependent gynecomastia. Life Sci. 2001;69(13):1465-9.
10. Rosen H, Webb ML, DiVasta AD, et al. Adolescent gynecomastia: not only an obesity issue. Ann Plast Surg. 2010;64(5):688-90.

11. Dimitrakakis C, Zhou J,Wang J, et al. A physiologic role for testosterone in limiting estrogenic stimulation of the breast. Menopause. 2003;10(4):292-8.

12. Pearlman G, Carlson HE. Gynecomastia: an update. The Endocrinologist. 2006;16(2):109-15. Available from: http://www.mendeley.com/ research/gynecomastia-update/. Accessed in 2011 (Oct 19).

13. Braunstein GD. Clinical practice. Gynecomastia. N Engl J Med. 2007;357(12):1229-37.

14. Narula HS, Carlson HE. Gynecomastia. Endocrinol Metab Clin North Am. 2007:36(2):497-519.

15. Thompson DF, Carter JR. Drug-induced gynecomastia. Pharmacotherapy. 1993;13(1):37-45.

16. Ismail AA, Barth JH. Endocrinology of gynaecomastia. Ann Clin Biochem. 2001;38(Pt 6):596-607.

17. Johnson RE, Murad MH. Gynecomastia: pathophysiology, evaluation, and management. Mayo Clin Proc. 2009;84(11):1010-5.

18. Braunstein GD. Environmental gynecomastia. Endocr Pract. 2008;14(4):409-11.

19. Durmaz E, Ozmert EN, Erkekoglu P, et al. Plasma phthalate levels in pubertal gynecomastia. Pediatrics. 2010;125(1):e122-9.

20. Stroheker T, Cabaton N, Nourdin G, et al. Evaluation of anti-androgenic activity of di-(2-ethylhexyl)phthalate. Toxicology. 2005;208(1):115-21.

21. Agency for Toxic Substances and Disease Registry. Toxicological profile for di-(2-ethylhexyl)-phthalate. Atlanta: Department of Health and Human Services, Public Health Service, Agency for Toxic Substances and Disease Registry; 2002. Available from: http://www. atsdr.cdc.gov/toxprofiles/tp9-p.pdf. Accessed in 2011 (Oct 19).

22. Sattin RW, Roisin A, Kafrissen ME, Dungan JB, Farer LS. Epidemic of gynecomastia among illegal Haitian entrants. Public Health Rep. 1984;99(5):504-10.

23. Brody SA, Loriaux DL. Epidemic of gynecomastia among haitian refugees: exposure to an environmental antiandrogen. Endocr Pract. 2003;9(5):370-5

24. Carlson HE, Kane P, Lei ZM, Li X, Rao CV. Presence of luteinizing hormone/human chorionic gonadotropin receptors in male breast tissues. J Clin Endocrinol Metab. 2004;89(8):4119-23.

25. Bird J, Li X, Lei ZM, et al. Luteinizing hormone and human chorionic gonadotropin decrease type 25 alpha-reductase and androgen receptor protein levels in women's skin. J Clin Endocrinol Metab. 1998:83(5):1776-82

26. Ruan W, Monaco ME, Kleinberg DL. Progesterone stimulates mammary gland ductal morphogenesis by synergizing with and enhancing insulin-like growth factor-l action. Endocrinology. 2005;146(3):1170-8.

27. Farthing MJ, Green JR, Edwards CR, Dawson AM. Progesterone, prolactin, and gynaecomastia in men with liver disease. Gut. 1982;23(4):276-9.

28. Nomura K, Suzuki H, Saji M, et al. High serum progesterone in hyperthyroid men with Graves' disease. J Clin Endocrinol Metab. 1988;66(1):230-2. 
29. Gill S, Peston D, Vonderhaar BK, Shousha S. Expression of prolactin receptors in normal, benign, and malignant breast tissue: an immunohistological study. J Clin Pathol. 2001;54(12):956-60.

30. Correll CU. Effect of hyperprolactinemia during development in children and adolescents. J Clin Psychiatry. 2008;69(8):e24.

31. Ormandy CJ, Hall RE, Manning DL, et al. Coexpression and crossregulation of the prolactin and sex steroid hormone receptors in breast cancer. J Clin Endocrinol Metab. 1997;82(11):3692-9.

32. Ruan W, Kleinberg DL. Insulin-like growth factor I is essential for terminal end bud formation and ductal morphogenesis during mammary development. Endocrinology. 1999;140(11):5075-81.

33. Braunstein GD. Gynecomastia. N Engl J Med. 1993;328(7):490-5.

34. Mazur T, Clopper RR. Pubertal disorders. Psychology and clinical management. Endocrinol Metab Clin North Am. 1991;20(1):211-30.

35. Harman SM, Metter EJ, Tobin JD, et al. Longitudinal effects of aging on serum total and free testosterone levels in healthy men. Baltimore Longitudinal Study of Aging. J Clin Endocrinol Metab. 2001;86(2):724-31.

36. Couillard C, Gagnon J, Bergeron J, et al. Contribution of body fatness and adipose tissue distribution to the age variation in plasma steroid hormone concentrations in men: the HERITAGE Family Study. J Clin Endocrinol Metab. 2000;85(3):1026-31.

37. Ford HC, Cooke RR, Keightley EA, Feek CM. Serum levels of free and bound testosterone in hyperthyroidism. Clin Endocrinol (Oxf). 1992;36(2):187-92.

38. Lanfranco F, Kamischke A, Zitzmann M, Nieschlag E. Klinefelter's syndrome. Lancet. 2004;364(9430):273-83.

39. Magro G, Gangemi P, Villari L, Greco P. Deciduoid-like stromal cells in a diabetic patient with bilateral gynecomastia: a potential diagnostic pitfall. Virchows Arch 2004;445(6):659-60.

40. García-Benayas T, Blanco F, Martín-Carbonero L, et al. Gynecomastia in HIV-infected patients receiving antiretroviral therapy. AIDS Res Hum Retroviruses. 2003;19(9):739-41.

41. Eckman A, Dobs A. Drug-induced gynecomastia. Expert Opin Drug Saf. 2008;7(6):691-702.

42. Goldman RD. Drug-induced gynecomastia in children and adolescents. Can Fam Physician. 2010;56(4):344-5.

43. Holzbeierlein JM. Managing complications of androgen deprivation therapy for prostate cancer. Urol Clin North Am. 2006;33(2):181-90, vi.

44. Sauer MA, Rifka SM, Hawks RL, Cutler GB Jr, Loriaux DL. Marijuana: interaction with the estrogen receptor. J Pharmacol Exp Ther 1983;224(2):404-7.

45. Basaria S. Androgen abuse in athletes: detection and consequences. J Clin Endocrinol Metab. 2010;95(4):1533-43.

46. Hines SL, Tan WW, Yasrebi M, DePeri ER, Perez EA. The role of mammography in male patients with breast symptoms. Mayo Clin Proc. 2007:82(3):297-300.

47. Dialani V, Baum J, Mehta TS. Sonographic features of gynecomastia. J Ultrasound Med. 2010;29(4):539-47.
48. Olsson H, Bladstrom A, Alm P. Male gynecomastia and risk for malignant tumours--a cohort study. BMC Cancer. 2002;2:26.

49. Fentiman IS, Fourquet A, Hortobagyi GN. Male breast cancer. Lancet. 2006;367(9510):595-604

50. Korde LA, Zujewski JA, Kamin L, et al. Multidisciplinary meeting on male breast cancer: summary and research recommendations. J Clin Oncol. 2010;28(12):2114-22.

51. Sasco AJ, Lowenfels AB, Pasker-de Jong P. Review article:epidemiology of male breast cancer. A meta-analysis of published case-control studies and discussion of selected aetiologic factors. Int J Cancer. 1993;53(4):538-49

52. Hultborn R, Hanson C, Köpfl, et al. Prevalence of Klinefelter's syndrome in male breast cancer patients. Anticancer Res. 1997;17(6D):4293-7.

53. Rohrich RJ, Ha RY, Kenkel JM, Adams WP Jr. Classification and management of gynecomastia: defining the role of ultrasoundassisted liposuction. Plast Reconstr Surg. 2003;111(2):909-23 discussion 924-5.

54. Ratnam BV. A new classification and treatment protocol for gynecomastia. Aesthet Surg J. 2009;29(1):26-31.

55. Simon BE, Hoffman S, Kahn S. Classification and surgical correction of gynecomastia. Plast Reconstr Surg. 1973;51(1):48-52.

56. Cordova A, Moschella F. Algorithm for clinical evaluation and surgical treatment of gynaecomastia. J Plast Reconstr Aesthet Surg. 2008;61(1):41-9.

57. Hammond DC. Surgical correction of gynecomastia. Plast Reconstr Surg. 2009;124(1 Suppl):61e-68e.

58. Jones DJ, Holt SD, Surtees P, Davison DJ, Coptcoat MJ. A comparison of danazol and placebo in the treatment of adult idiopathic gynaecomastia: results of a prospective study in 55 patients. Ann $\mathrm{R}$ Coll Surg Engl. 1990;72(5):296-8

59. Buckle R. Danazol therapy in gynaecomastia; recent experience and indications for therapy. Postgrad Med J. 1979:55 Suppl 5:71-8.

60. Eberle AJ, Sparrow JT, Keenan BS. Treatment of persistent pubertal gynecomastia with dihydrotestosterone heptanoate. J Pedriat. 1986;109(1):144-9.

61. Alagaratnam TT. Idiopathic gynecomastia treated with tamoxifen: a preliminary report. Clin Ther. 1987;9(5):483-7.

62. McDermott MT, Hofeldt FD, Kidd GS. Tamoxifen therapy for painful idiopathic gynecomastia. South Med J. 1990;83(11):1283-5.

63. Khan HN, Rampaul R, Blamey RW. Management of physiological gynaecomastia with tamoxifen. Breast. 2004;13(1):61-5.

64. Ting AC, Chow LW, Leung YF. Comparison of tamoxifen with danazol in the management of idiopathic gynecomastia. Am Surg. 2000;66(1):38-40

65. Lawrence SE, Faught KA, Vethamuthu J, Lawson ML. Beneficial effects of raloxifene and tamoxifen in the treatment of pubertal gynecomastia. J Pediatr. 2004;145(1):71-6.

66. Riepe FG, Baus I, Wiest $S$, et al. Treatment of pubertal gynecomastia with the specific aromatase inhibitor anastrozole. Horm Res. 2004;62(3):113-8. 
67. Mauras N, Bishop K, Merinbaum D, et al. Phamacokinetics and pharmacodynamics of anastrozole in pubertal boys with recentonset gynecomastia. J Clin Endocrinol Metab. 2009;94(8):2975-8.

68. Plourde PV, Reiter EO, Jou HC, et al. Safety and efficacy of anastrozole for the treatment of pubertal gynecomastia: a randomized, double-blind, placebo-controlled trial. J Clin Endocrinol Metab. 2004;89(9):4428-33.

69. Petty PM, Solomon M, Buchel EW, Tran NV. Gynecomastia: evolving paradigm of management and comparison of techniques. Plast Reconstr Surg. 2010;125(5):1301-8.

70. Boccardo F, Rubagotti A, Battaglia M, et al. Evaluation of tamoxifen and anastrozole in the prevention of gynecomastia and breast pain induced by bicalutamide monotherapy of prostate cancer. J Clin Oncol. 2005;23(4):808-15.

71. Laituri CA, Garey CL, Ostlie DJ, et al. Treatment of adolescent gynecomastia. J Pediatr Surg. 2010;45(3):650-4.

72. Pitanguy I. Transareolar incision for gynecomastia. Plast Reconstr Surg. 1966;38(5):414-9.

73. Davidson BA. Concentric circle operation for massive gynecomastia to excise the redundant skin. Plast Reconstr Surg. 1979;63(3):350-4.

74. Gheita A. Gynecomastia: the horizontal ellipse method for its correction. Aesthetic Plast Surg. 2008;32(5):795-801.

75. Abramo AC. Axillary approach for gynecomastia liposuction. Aesthetic Plast Surg. 1994;18(3):265-8.

76. Ohyama T, Takada A, Fujikawa M, Hosokawa K. Endoscope-assisted transaxillary removal of glandular tissue in gynecomastia. Ann Plast Surg. 1998;40(1):62-4.

77. Chiu DT, Siegel HW. The pinwheel technique: an adjunct to the periareolar approach in gynecomastia resection. Ann Plast Surg. 1999:42(5):465-9.

78. Pine JL, Smith LJ, Haws MJ, Gingrass MK. Ultrasound-assisted lipoplasty. Plast Surg Nurs. 2003;23(3):101-8; quiz 109.

79. Maidment SL. Question 2. Which medications effectively reduce pubertal gynaecomastia? Arch Dis Child. 2010;95(3):237-9.

80. Handschin AE, Bietry D, Hüsler R, Banic A, Constantinescu M. Surgical management of gynecomastia--a 10-year analysis. World J Surg. 2008;32(1):38-44.

81. LanitisS,StarrenE,ReadJ,etal.SurgicalmanagementofGynaecomastia: outcomes from our experience. Breast. 2008;17(6):596-603.

82. Gasperoni G, Salgarello M, Gasperoni P. Technical refinements in the surgical treatment of gynecomastia. Ann Plast Surg. 2000;44(4):455-8.

83. Wiesman IM, Lehman JA Jr, Parker MG, et al. Gynecomastia: an outcome analysis. Ann Plast Surg. 2004;53(2):97-101.

84. Fruhstorfer BH, Malata CM. A systematic approach to the surgical treatment of gynaecomastia. Br J Plast Surg. 2003;56(3):237-46.

85. Lejour M. Evaluation of fat in breast tissue removed by vertical mammoplasty. Plast Reconstr Surg. 1997;99(2):386-93.

86. GohT, Tan BK, Song C. Use of the microdebrider for treatment of fibrous gynaecomastia. J Plast Reconstr Aesthet Surg. 2010;63(3):506-10.
87. Hamilton S, Gault D. The tuberous male breast. $\mathrm{Br} J$ Plast Surg. 2003;56(3):295-300

\section{Sources of funding: None}

Conflict of interest: None

Date of first submission: July 11, 2011

Last received: August 29, 2011

Accepted: December 27, 2011

\section{Address for correspondence:}

Alfredo Carlos Barros

Rua Dr. Renato Paes de Barros, 750 - apto 35

Itaim Bibi — São Paulo (SP) — Brasil

CEP : 04530-001

Tel. (+55 11) 3071.2331

Fax: (+55 11) 3078.1763

E-mail: clinab@terra.com.br 